\title{
Antioxidant Bioavailability and Rapid Immune-Modulating Effects After Consumption of a Single Acute Dose of a High-Metabolite Yeast Immunogen: Results of a Placebo-Controlled Double-Blinded Crossover Pilot Study
}

\author{
Gitte S. Jensen, ${ }^{1}$ Kimberlee A. Redman, ${ }^{1}$ Kathleen F. Benson, Steve G. Carter, \\ Marcie A. Mitzner, Stuart Reeves, ${ }^{2}$ and Larry Robinson ${ }^{2}$ \\ ${ }^{I}$ NIS Labs, Klamath Falls, Oregon, USA. \\ ${ }^{2}$ Embria Health Sciences, Ankeny, Iowa, USA.
}

\begin{abstract}
The objective of this pilot study was to investigate the acute effects on circulating lymphocyte subsets, antioxidant status, and cytokine profile after consumption of EpiCor ${ }^{\circledR}$ (EP) (Embria Health Sciences, Ankeny, IA, USA), a dried fermentate produced from Saccharomyces cerevisiae, using a placebo-controlled randomized crossover study design with 12 healthy adult human subjects. EP contains high levels of bioavailable antioxidants and strongly activates natural killer (NK) cells in vitro. EP consumption has been shown to increase erythrocyte hematocrit levels, boost mucosal immune protection, reduce cold/flu symptoms, reduce seasonal allergy symptoms and the need for rescue medication, and increase salivary secretory immunoglobulin A levels. This warranted further study on immune effects in humans. A within-subject analysis of data collected before and at 1 and 2 hours after consumption of a single dose of $500 \mathrm{mg}$ of EP versus placebo was performed. A transient reduction in circulating T and NK cell numbers was observed 2 hours post-consumption, suggesting that homing and recirculation of these cells, as part of healthy immune surveillance, were supported by EP. The increased expression of activation markers on the $\mathrm{CD}^{-} \mathrm{CD}^{-} 6^{+} \mathrm{NK}$ cell population was significant for CD69 at 1 hour post-consumption (CD25, $P<.07$; CD69, $P<.05)$, whereas for CD25 it was significant at 2 hours after consumption $(\mathrm{CD} 25, P<.03$; CD69, $P<.15)$. A rapid increase in serum interferon- $\gamma$ was observed at 1 hour post-consumption $(P<.07$; after removal of two outlying data sets, $P<.05)$ and may have contributed to the effects seen on NK and T cell subsets. Significant increase in serum antioxidant protection was seen 2 hours after consumption $(P<.04)$. Thus consumption of a single $500 \mathrm{mg}$ dose of EP provides a rapid and transient effect on the trafficking and activation status of specific lymphocyte subsets, as well as increased antioxidant protection.
\end{abstract}

KEY WORDS: • antioxidants $\bullet$ CD25 $\bullet$ CD69 $\bullet$ cytokines $\bullet$ EpiCor ${ }^{\circledR} \bullet$ natural killer cells $\bullet$ Th1/Th2 $\bullet$ T lymphocytes

\section{INTRODUCTION}

$\mathbf{T}$ HE MULTIFACETED HEALTH IMPLICATIONS of viral diseases span a vast spectrum throughout poverty-stricken as well as industrialized countries. Acute viral diseases include those due to rhinovirus and rapidly mutating influenza virus strains. Chronic viral infections include those due to hepatitis virus, human immune deficiency virus, and many omnipresent viruses such as the herpes family of viruses. The viral load, along with confounding factors, may lead to increased risks of development of autoimmune disease and other chronic illness or cancer in some individuals. There is also a growing suspicion that chronic obscure viruses may be involved, directly or indirectly, in chronic pain and fatigue syndromes. ${ }^{1-3}$

Manuscript received 10 July 2010. Revision accepted 18 February 2011

Address correspondence to: Gitte S. Jensen, Ph.D., NIS Labs, 1437 Esplanade, Klamath Falls, OR 97601, USA, E-mail: gitte@nislabs.com
The role of natural killer (NK) cells in combating viral disease is known to involve many aspects of NK cell biology and interaction with other cell types such as macrophages and dendritic cells. The production of interferons (IFNs), combined with NK cell trafficking, is an important aspect of immune surveillance against viral infections. NK cells are also an important part of eliminating malignant cells ${ }^{4,5}$ and reduced NK cell numbers and function are reported in many cancers. ${ }^{6}$

The immune surveillance activities of many lymphocyte subsets, including NK and T lymphocytes, are closely regulated by the central nervous system. There is a distinct circadian rhythm in levels and activity of T and NK cells in the blood circulation, ${ }^{7,8}$ including opposing effects on naive and memory $\mathrm{T}$ cell subsets, where naive cells appear in the blood circulation at low levels during sleep and a gradual increase in circulating cells during waking hours, and the opposite effect is seen for memory T cells. ${ }^{9}$ This suggests that immune surveillance, involving exit from blood circulation and migration through tissue, is regulated, and 
individual fluctuations must be taken into account when analyzing a nutritional product's effect on numbers of leukocyte subsets in blood circulation.

Furthermore, NK cell biology is directly affected by psychological stressors and sleep disturbances. Acute stress results in reduced lymphocyte trafficking and surveillance, whereas relaxation supports immune surveillance, seen as reduced levels of circulating NK cells. Sleep disturbances are involved in reduced NK cell function in healthy volunteers ${ }^{10}$ and accumulation of NK cells in the blood circulation in diabetics. ${ }^{11}$ There is a documented link among reduced NK cell function, low melatonin levels, ${ }^{12}$ and high cortisol levels. ${ }^{13}$ Therefore, studies on acute changes to NK activation status and trafficking need to be carefully controlled for environmental stressors.

Antioxidant uptake and protection in blood and tissue are important factors for immune health. Poor antioxidant status has been related to chronic inflammatory problems and cardiovascular disease. ${ }^{14}$ Bioavailability of antioxidants in vivo is the desired end point for antioxidant documentation for nutritional products. The Cell-based Antioxidant Protection in Erythrocytes (CAP-e) assay (patent pending, NIS Labs, Klamath Falls, OR, USA) has been shown to be useful for evaluating rapid changes in antioxidant status after consumption of a single dose of antioxidant-rich foods. ${ }^{15}$ The data reflect not only the uptake of antioxidants involved in blood circulation, but they also measure those antioxidants that are present in serum and able to enter into and protect cells from oxidative damage. ${ }^{16}$

The Saccharomyces cerevisiae-based dry fermentate nutritional product EpiCor ${ }^{\circledR}$ (EP) (Embria Health Sciences, Ankeny, IA, USA) has a high antioxidant content as evaluated by the chemical oxygen radical absorbance capacity assay ${ }^{17}$ and was shown to possess antioxidants capable of entering into and protecting live cells in vitro. ${ }^{16}$ Another yeast-based extract has similar immune-activating properties in vitro. ${ }^{18}$

EP has been used in previous studies relating to immune health and function. A 5-week placebo-controlled pilot study involved daily consumption of $500 \mathrm{mg}$ and showed trends of increased mucosal protection and reduced allergies. ${ }^{19}$ This was followed by three larger studies. Two 12week, randomized, double-blinded, placebo-controlled clinical trials ${ }^{20,21}$ used $500 \mathrm{mg} /$ day and found that subjects had significantly fewer cold/flu symptoms than subjects taking placebo. Another 12-week, randomized, doubleblinded, placebo-controlled study investigated the effects of $\mathrm{EP}$ on allergic rhinitis: ${ }^{22}$ it found EP to significantly reduce the mean severity of specific allergic rhinitis symptoms. Significant outcomes observed included reduced nasal congestion and rhinorrhea and self-reported parameters such as total number of days with nasal congestion and nasal secretions on a quality of life questionnaire, as well as reduced use of rescue medication. ${ }^{22}$

The purpose of the clinical study reported here was to expand on previous in vitro and clinical work examining the effects of EP on immune cells in vivo, with a special focus on NK cell activation, antioxidant status, and cytokine profile.

\section{MATERIALS AND METHODS}

\section{Buffers and media}

Phosphate-buffered saline (PBS) (pH 7.4), sodium azide, gallic acid, bovine serum albumin, Histopaque ${ }^{\circledR} 1077$, and Histopaque 1119 were obtained from Sigma-Aldrich (St. Louis, MO, USA). Dichlorofluorescein diacetate was obtained from Molecular Probes (Eugene, OR, USA), a subdivision of Invitrogen (Carlsbad, CA, USA). 2,2'-Azobis(2-amidinopropane) dihydrochloride (AAPH) was obtained from Wako Chemicals (Richmond, VA, USA). The S. cerevisiae-based fermentation product EP was obtained from Embria Health Sciences. The placebo was encapsulated white rice flour, shown to possess no measurable antioxidant protection of live cells in vitro. For the clinical study, both $\mathrm{EP}$ and placebo were encapsulated in non-transparent blue capsules in order to blind subjects and clinic staff.

\section{Monoclonal antibodies}

The following monoclonal antibodies were purchased from Becton-Dickinson (San Jose, CA, USA): CD25-fluorescein isothiocyanate (FITC), CD34-FITC, CD45-FITC, CD69-FITC, CD56-phycoerythrin, CD3-peridinin-chlorophyllprotein complex (PerCP), CD45-PerCP, and isotype control antibodies.

\section{Consumables}

Two different types of consumables were prepared: EP and placebo. EP is a proprietary high-metabolite S. cerevisiae-based dried nutritional fermentate. As a placebo, white rice flour was used. Because EP is dark brown and the rice flour is white, non-transparent, blue capsules were used for encapsulating. Thus, at each visit, each person would consume a single blue capsule in the presence of the study coordinator. Study participants, nurses, and laboratory assistants were blinded so nurses and staff interacting with the study participants, as well as the staff processing samples, conducting tests, and performing data entry and analysis, were unaware of the content of capsules.

\section{Study design}

A double-blinded randomized placebo-controlled crossover study design was used (Fig. 1). Twelve people were recruited for the study upon informed consent approved by the Sky Lakes Medical Center (Klamath Falls) Institutional Review Board (protocol number FWA 2603) (Table 1).

The following exclusion criteria were used: under 18 or over 55 years of age, pregnancy, severe asthma and allergies requiring daily medication, any known chronic illness, frequent recreational drug use, impaired digestive function (including previous major gastrointestinal surgery), and allergies to yeast.

The volunteers were scheduled on two study days at least 2 weeks apart. Testing was always performed at the same time of the day (8-11 a.m.) to minimize the effect of circadian fluctuations. Because of the interference from exercise $^{23}$ and stress ${ }^{9,24-26}$ with the release versus homing of 


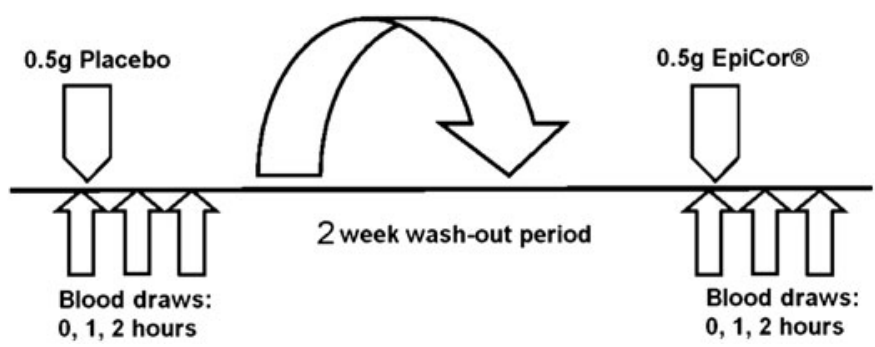

FIG. 1. Diagram outlining the double-blinded placebo-controlled study design. The order in which each subject consumed placebo versus EpiCor was randomized so half the number of subjects received placebo on the first study day, and the other half of the subjects received EpiCor on the first study day.

lymphocytes, effort was taken to minimize any physical and mental stress prior to and during testing. In addition, on each study day, volunteers were instructed to complete a questionnaire aimed at monitoring any exceptional stress-related circumstances that might affect the person on that particular study day. Predetermined criteria for exclusion from data analysis included sleep deprivation and acute anxiety. After completing the questionnaire, volunteers were instructed to remain quiescent for 3 hours, comfortably seated in a chair. After the first hour, the baseline blood sample was drawn. Immediately after the baseline sample was drawn, a consumable was provided with water. Blood samples were drawn at 1 and 2 hours after ingestion of the consumable. At each blood draw, $8 \mathrm{~mL}$ of blood was drawn into serum separator tubes: $6 \mathrm{~mL}$ of blood was drawn into heparin, and $2 \mathrm{~mL}$ blood was drawn into EDTA. Serum was harvested and kept frozen at $-80^{\circ} \mathrm{C}$ until testing for antioxidant status and cytokine profile. The blood drawn into EDTA was used for obtaining a complete blood count (CBC) with differential, using a Coulter counter (Micro Diff II, Beckman Coulter, Brea, CA, USA). All CBCs were performed in triplicate within an hour of drawing the sample.

\section{$C B C$ with differential}

The EDTA samples were used to obtain triplicate CBCs with differential. These data were used to examine whether EP consumption affects the numbers of white blood cells, granulocytes, erythrocytes, monocytes, and lymphocytes. The data also served to calculate numbers of circulating $\mathrm{T}$ cells, NK cells, and stem cells, by merging flow cytometric data with the CBC data.

Table 1. Description of the Study Population

\begin{tabular}{lccc}
\hline & \multicolumn{3}{c}{ Subjects } \\
\cline { 2 - 4 } & All $(\mathrm{n}=12)$ & Males $(\mathrm{n}=3)$ & Females $(\mathrm{n}=9)$ \\
\hline Age range (years) & $18-54$ & & \\
Age (years) & $35.6 \pm 13.3$ & $20.3 \pm 2.5$ & $40.7 \pm 11.2$ \\
Height $(\mathrm{cm})$ & $169.4 \pm 15.2$ & $191.4 \pm 12.8$ & $162.1 \pm 6.2$ \\
Weight $(\mathrm{kg})$ & $69.5 \pm 16.4$ & $90.8 \pm 18.2$ & $62.4 \pm 7.8$ \\
BMI $\left(\mathrm{kg} / \mathrm{m}^{2}\right)$ & $24.0 \pm 2.8$ & $24.6 \pm 1.7$ & $23.8 \pm 3.2$ \\
\hline
\end{tabular}

Data are mean \pm SD values.

BMI, body mass index.

\section{Immunostaining}

Freshly isolated peripheral blood mononuclear cells were placed in a V-bottom 96-well plate (NUNC, Copenhagen, Denmark) and washed in IF buffer (PBS containing 1\% bovine serum albumin and $0.02 \%$ sodium azide). Cells were resuspended in $0.05 \mathrm{~mL}$ of IF buffer, monoclonal antibodies were added, and plates were incubated in the dark at room temperature for 10 minutes. The cells were washed twice with an additional $0.15 \mathrm{~mL}$ of PBS with $0.02 \%$ sodium azide. Following centrifugation and aspiration of supernatant, cells were resuspended in $0.05 \mathrm{~mL}$ of PBS with $0.02 \%$ azide and transferred to $5-\mathrm{mL}$ polystyrene tubes each containing $0.4 \mathrm{~mL}$ of $1 \%$ formalin. Samples were stored in the dark and acquired by flow cytometry within 24 hours using a FACSCalibur ${ }^{\mathrm{TM}}$ flow cytometer (Becton-Dickinson). Files of 200,000 events were collected on each triplicate sample. The percentages of $\mathrm{CD}^{+}, \mathrm{CD}^{-} \mathrm{CD}^{+} 6^{+}$, and $\mathrm{CD} 34^{+} \mathrm{CD} 45^{\mathrm{dim}}$ subsets were analyzed separately and were analyzed again after multiplying with the lymphocyte cell counts, as obtained from the average of the triplicate lymphocyte counts obtained by the $\mathrm{CBC}$ with differential. For the $\mathrm{CD}^{+}$and $\mathrm{CD}^{-} \mathrm{CD}^{-} 6^{+}$, subsets, the expression of the two activation markers CD69 and CD25 was evaluated. Analysis was performed using FlowJo (Tree Star Inc., Ashland, OR, USA) software.

\section{Antioxidant status}

Preparation of antioxidant standard. Gallic acid was prepared immediately prior to use by weighing $425 \mathrm{mg}$ into methanol $(5 \mathrm{~mL})$. Gentle agitation was performed until all crystals were dissolved, and $0.4 \mathrm{~mL}$ was transferred to PBS $(49.6 \mathrm{~mL})$.

Purification of red blood cells. Red blood cells (RBCs) were obtained from a healthy human volunteer after informed consent, as approved by the Sky Lakes Medical Center Institutional Review Board. Peripheral venous blood was drawn into sodium heparin and layered onto a double-gradient of Histopaque 1119 and 1077. The vials were centrifuged and spun at 2,400 rpm using a four-place swinging rotor for the IEC Centra MP4 centrifuge (Thermo Fisher Scientific, Waltham, MA) for 25 minutes. The peripheral blood mononuclear cellrich upper interface and the polymorphonuclear neutrophil-rich lower interfaces were removed using sterile transfer pipettes. Packed RBCs were washed twice in PBS without calcium or magnesium and spun at 2,400 rpm using a four-place swinging rotor for the IEC Centra MP4 centrifuge (Thermo Fisher Scientific) for 10 minutes. Then the core of the packed RBCs was transferred into new vials and again washed twice in PBS without calcium or magnesium and spun at 2,400 rpm using a four-place swinging rotor for the IEC Centra MP4 centrifuge (Thermo Fisher Scientific) for 10 minutes. Aliquots were prepared by transferring packed RBCs $(0.2 \mathrm{~mL})$ into $3 \mathrm{~mL}$ of sterile PBS in sterile vials. Aliquots were stored at $4^{\circ} \mathrm{C}$ until use.

CAP-e assay. An aliquot of RBCs was washed twice in physiological saline. A cell suspension was then prepared for the CAP-e assay by adding packed RBCs $(0.1 \mathrm{~mL})$ to PBS 
$(10 \mathrm{~mL})$. The cell suspension was distributed in a V-bottom 96-well microtiter plate. Twelve wells were not treated with any source of antioxidants and served as negative controls (six wells) and positive controls (six wells) for minimum versus maximum oxidative damage. Twelve wells were treated with a standard source of a known antioxidant (gallic acid) across six different serial dilutions, where each dilution was tested in duplicate. The remaining wells were treated with serum, where each serum sample collected during the study was tested in quadruplicate. Cells were incubated with serum for 20 minutes in the accelerated CAP-e assay protocol. Antioxidants not absorbed by the cells were removed by washing twice in PBS by centrifuging at 2,400 rpm for 2.5 minutes using a four-place swinging rotor for the IEC Centra MP4 centrifuge (Thermo Fischer Scientific). The cells were lysed, and the precursor dye was added to the wells. Incubation was performed at room temperature for 15 minutes. Oxidative damage was introduced using the peroxyl free radical generator AAPH for 1 hour. The green fluorescence intensity, as a measure of oxidative damage, was measured at $488 \mathrm{~nm}$ using a Tecan (Zurich, Switzerland) Spectrafluor plate reader (40 flashes, optimal gain). Analysis was performed where the mean fluorescence intensity (MFI) of cells treated with serum was compared with that of cells treated with AAPH alone, to establish the cellular antioxidant protection provided by each serum sample.

\section{Thelper 1/2 cytokine profile}

Serum separator tubes were allowed to sit for 60 minutes at room temperature to facilitate proper coagulation; the vials were then centrifuged at $3,000 \mathrm{rpm}$ using a four-place swinging rotor for the IEC Centra MP4 centrifuge (Thermo Fisher Scientific) for 15 minutes. Serum was harvested using a sterile transfer pipette and aliquoted before freezing at $-80^{\circ} \mathrm{C}$. The serum was used for cytokine analysis where the relative levels of the six cytokines interleukin (IL)-2, IL-4, IL-6, IL-10, tumor necrosis factor- $\alpha$, and IFN- $\gamma$ were measured using a flow cytometry-based bead array kit (human T helper [Th] 1/ Th2 cytokine kit II, BD Biosciences, San Jose). Samples were tested in duplicate according to the manufacturer's specifications, and data were acquired immediately by flow cytometry, using a FACSCalibur flow cytometer. The analysis was performed using FlowJo software.

\section{Statistical analysis}

Statistical analysis involved simple comparisons between two mean values and was performed using Microsoft (Redmond, WA, USA) Excel. Statistical significance was tested using Student's $t$ test with a $P$ value of $<0.5$ indicating a significant difference between two data sets.

\section{RESULTS}

\section{Changes in circulating leukocyte subsets and erythrocytes}

No statistically significant changes were seen in the absolute or relative changes in the number of white blood cells (leukocytes), RBCs (erythrocytes), or granulocytes, when
Table 2. Changes in Circulating Cell Subsets After Consumption of EpiCor Versus Placebo

\begin{tabular}{|c|c|c|c|}
\hline & \multicolumn{2}{|c|}{$\mathrm{P}$ value } & \multirow[b]{2}{*}{$\%$ change } \\
\hline & 1 hour & 2 hours & \\
\hline White blood cells & NS & NS & \\
\hline Red blood cells & NS & NS & \\
\hline Granulocytes & NS & NS & \\
\hline Lymphocytes & NS & $<.10$ & -9.42 \\
\hline $\mathrm{CD}^{+}{ }^{+} \mathrm{T}$ cells & NS & $<.01$ & -13.86 \\
\hline $\mathrm{CD}^{-}{ }^{-} \mathrm{CD} 6^{+} \mathrm{NK}$ cells & NS & $<.05$ & $-26.66^{\mathrm{a}}$ \\
\hline $\mathrm{CD}_{3} 4^{+}$stem cells & NS & $<.12$ & $-8.91^{\mathrm{a}}$ \\
\hline
\end{tabular}

The percentage change and statistical significance were obtained on the study population of 12 volunteers unless noted otherwise. The within-subject analysis and resulting $P$ value were obtained by performing the paired $t$ test.

${ }^{a}$ Results for $\mathrm{CD}^{-} \mathrm{CD}^{+} 6^{+}$natural killer (NK) cells and CD34 ${ }^{+}$stem cells were obtained on the study population of 10 people, after removal of data from volunteers 4 and 7 based on noncompliance on one of the two test days.

NS, not significant.

comparing baseline data with 1-hour and 2-hour blood draws after consumption of EP versus placebo using a paired $t$ test (Table 2).

\section{Changes in circulating lymphocyte subsets}

Using the lymphocyte counts obtained by the CBC, combined with the evaluation of lymphocyte subsets from the flow cytometry analysis, specific changes were seen among the $\mathrm{CD}^{+}{ }^{+} \mathrm{T}$ cell and the $\mathrm{CD}^{-} \mathrm{CD}^{-} 6^{+} \mathrm{NK}$ cell subsets. The number of circulating $\mathrm{CD}^{+} \mathrm{T}$ lymphocytes decreased at 1 hour in the EP group when compared with placebo, and further decrease was seen at 2 hours, at which time the difference between changes after consumption of placebo and EP was highly significant $(P<.01)$ (Table 2 and Fig. 2). The number of NK cells showed a trend toward reduction in the EP group when compared with the placebo group at 2 hours post-consumption. With the removal of two data sets from the analysis, the within-subject analysis revealed statistical significance $(P<.05)$ (Table 2 and Fig. 3$)$.

A mild reduction was seen for the numbers of $\mathrm{CD} 34^{+}$ circulating stem cells at 2 hours; however, the observation did not reach statistical significance $(P<.15)$ (Table 2$)$.

\section{Changes in activation status of circulating $N K$ and $T$ cells}

The $\mathrm{CD}^{+}{ }^{+} \mathrm{T}$ cell population and the $\mathrm{CD}^{-} \mathrm{CD}^{-} 6^{+} \mathrm{NK}$ cell population were analyzed for expression of the two activation markers CD25 and CD69. No significant changes were seen on the $\mathrm{T}$ cells. In contrast, both markers were expressed at higher levels on NK cells after consumption of EP than after consumption of placebo. The relative increase in expression of the CD25 marker on NK cells is shown in Figure 4 . This effect was already seen at 1 hour after consumption $(P<.07)$ and reached statistical significance at 2 hours after consumption $(P<.05)$. The relative increase in expression of the CD69 marker on NK cells is shown in Figure 5. This effect was already statistically significant at 1 

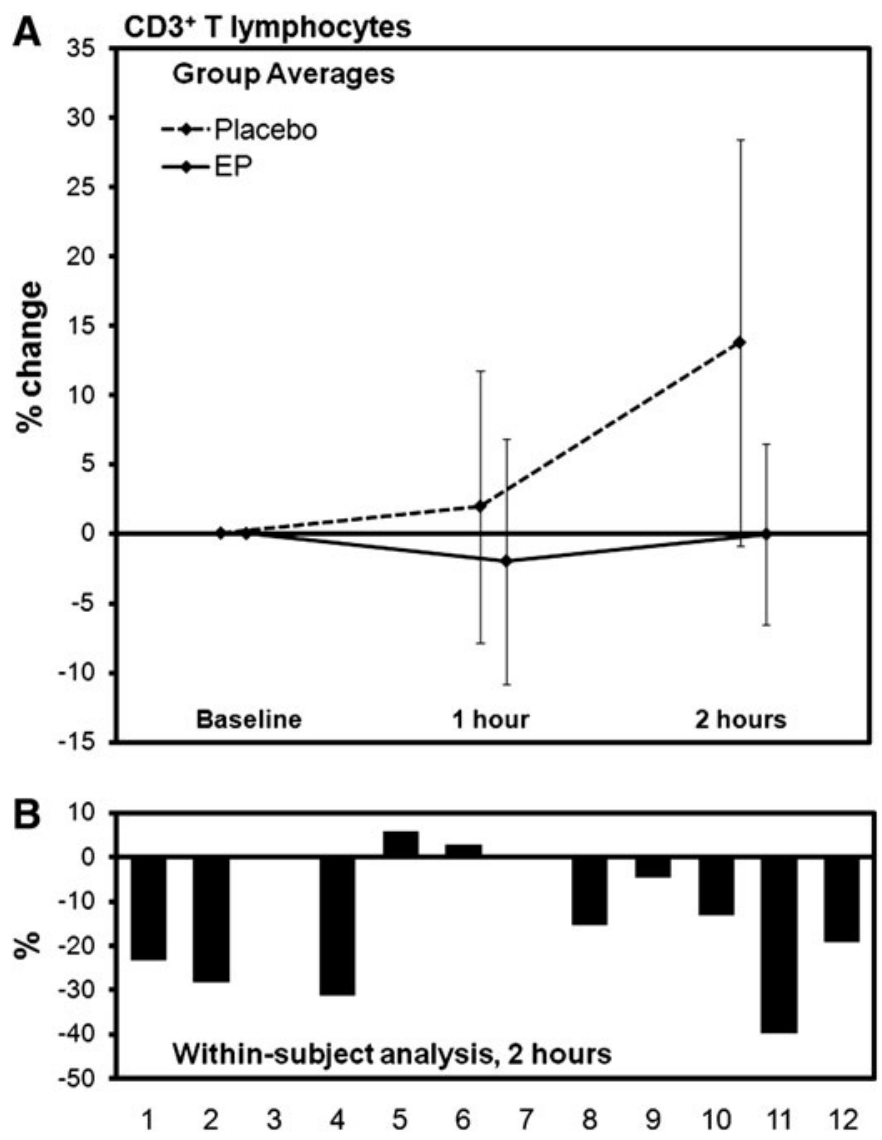

FIG. 2. Changes in the number of circulating $T$ cells after consumption of placebo and $500 \mathrm{mg}$ of EpiCor (EP). (A) The group averages are shown for changes seen after consumption of placebo versus EP (mean $\pm \mathrm{SD})$. (B) The individual changes were compared for each subject to evaluate the change in each subject's response to $\mathrm{EP}$ in comparison with the same subject's response to placebo. Using a within-subject analysis, a statistically significant reduction in $\mathrm{T}$ cell numbers was seen for EP at 2 hours post-consumption $(P<.01)$, suggesting increased immune surveillance.

hour after consumption $(P<.05)$ but was returning to normal at 2 hours after consumption $(P<.15)$.

\section{Antioxidant uptake}

We used the CAP-e assay to test in vivo antioxidant protection capacity of EP. The serum samples were tested in an accelerated CAP-e assay protocol using freshly isolated erythrocytes. Each serum sample was tested in quadruplicate. The data from each person's baseline serum sample were indicative of this person's antioxidant protection capacity before consumption of either EP or placebo. The level of oxidative damage in samples where cells were treated with post-consumption serum samples was compared with the oxidative damage in samples exposed to baseline serum. Each person's start level was set to " 0 ," and the relative change (increase, decrease) in serum antioxidant protection capacity was calculated. The average and SD values are shown in Figure 6. Consumption of $500 \mathrm{mg}$ of EP resulted in
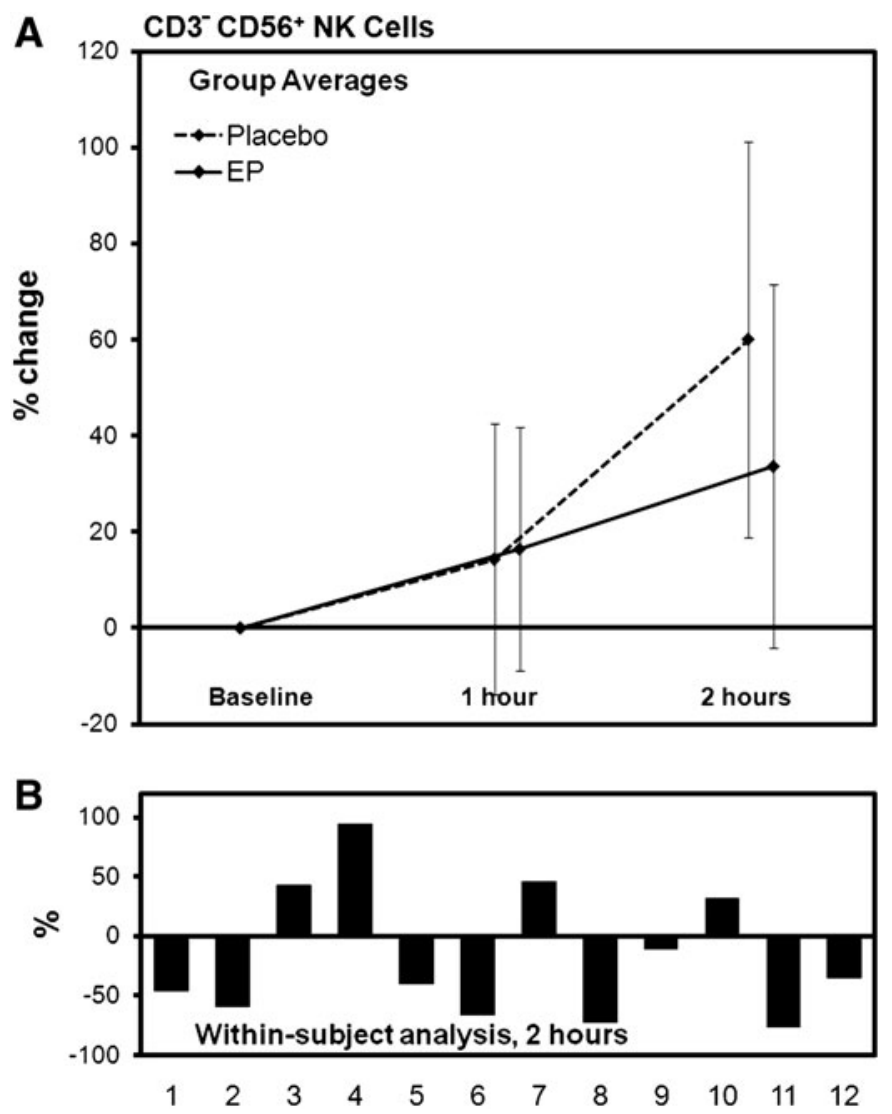

FIG. 3. Changes in NK cell counts after consumption of placebo and $500 \mathrm{mg}$ of EP. (A) The group averages are shown for changes seen after consumption of placebo versus EP (mean \pm SD). (B) The individual changes were compared for each subject to evaluate the change in each subject's response to EP in comparison with the same subject's response to placebo. Using a within-subject analysis, a statistically significant reduction in NK cell numbers was seen for EP at 2 hours post-consumption $(P<.05)$, suggesting increased trafficking of NK cells.

a statistically significant increase in antioxidant protection $(P<.04)$.

\section{Changes in serum Th1/Th2 cytokine levels}

Serum was analyzed for the panel of Th1/Th2 cytokines IL-2, IL-4, Il-6, IL-10, tumor necrosis factor- $\alpha$, and IFN- $\gamma$, using a cytokine bead array for flow cytometry. Each person's changes after consumption of placebo versus EP were evaluated, and the normalized data for the study population are shown in Table 3. There was a trend to reduced levels of IL-6 and IL-10 at 2 hours, when comparing each person's response to EP versus placebo. The changes did not reach statistical significance for either IL-6 $(P<.1)$ or for IL-10 $(P<.2)$. A transient increase in IFN- $\gamma$ was seen at 1 hour $(P<.07)$, but levels returned to normal at 2 hours. The increase in IFN- $\gamma$ was re-analyzed after removal of two outliers, and the re-analysis of the remaining 10 subjects reached statistical significance $(P<.05)$. 
A
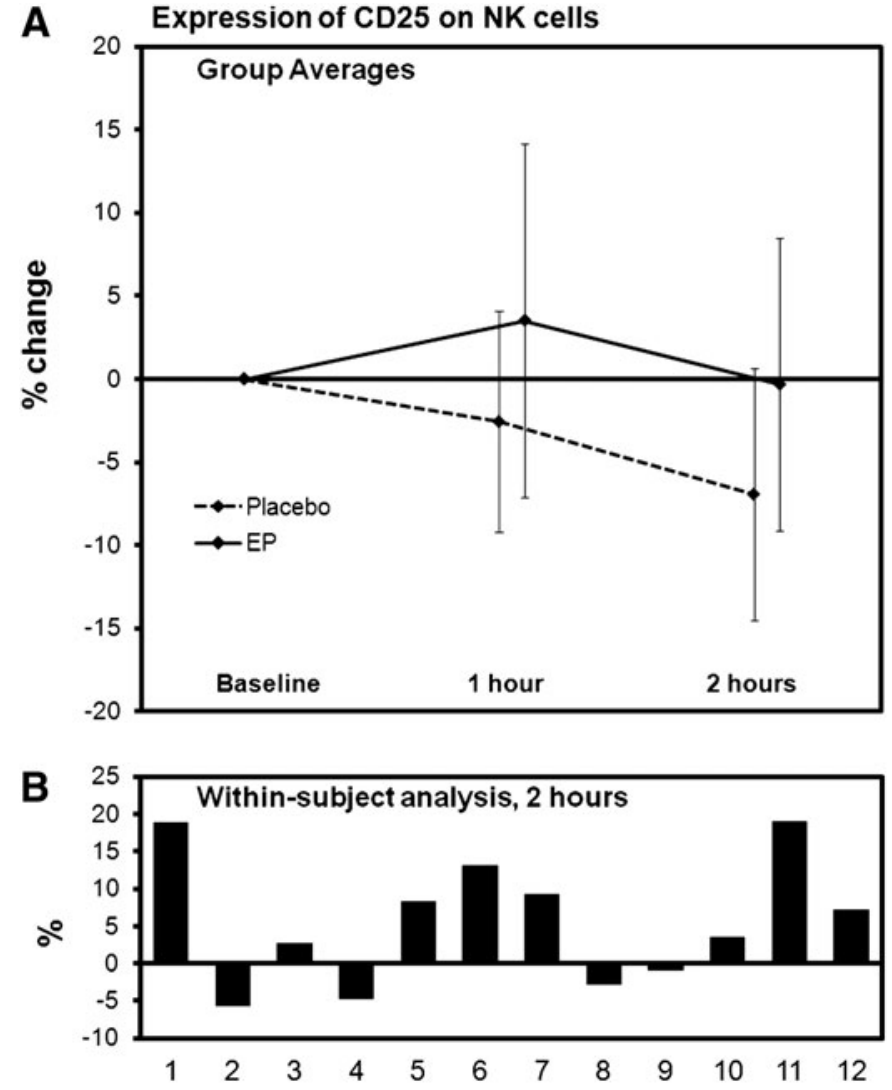

FIG. 4. Changes in expression of the CD25 activation marker on $\mathrm{CD}^{-} \mathrm{CD}^{-} 6^{+} \mathrm{NK}$ cells after consumption of placebo and $500 \mathrm{mg}$ of EP. (A) The group averages are shown for changes seen after consumption of placebo versus EP (mean $\pm \mathrm{SD}$ ). (B) The individual changes were compared for each subject to evaluate the change in each subject's response to EP in comparison with the same subject's response to placebo. These data were then analyzed using a withinsubject paired $t$ test. The EP-induced increase over placebo was not significant at 1 hour $(P<.07)$ but reached statistical significance at 2 hours $(P<.05)$.

\section{DISCUSSION}

In this study we have shown evidence for rapid changes in serum antioxidant status, cytokine levels, and immune surveillance after consumption of a single dose of the immunogenic yeast product EP, compared with placebo. This is a direct extension of our previous publication showing direct activation of NK cells in vitro ${ }^{17}$ and in vivo. ${ }^{19}$ These combined data may help explain data from other clinical studies where reduced incidence and duration of cold/flu were observed..$^{20,21}$

The acute effects of EP consumption included a highly significant decrease in numbers of circulating $T$ lymphocytes, and a trend toward a reduced number of circulating NK cells suggests that ingestion of a single dose of EP led to increased $\mathrm{T}$ and NK cell trafficking and homing into tissue. The $\mathrm{T}$ and NK cells observed in the circulation at 1 and 2 hours after consumption had already increased expression of activation markers at 1 hour after consumption. The expression of the IL-2 receptor CD25 and of the marker CD69,
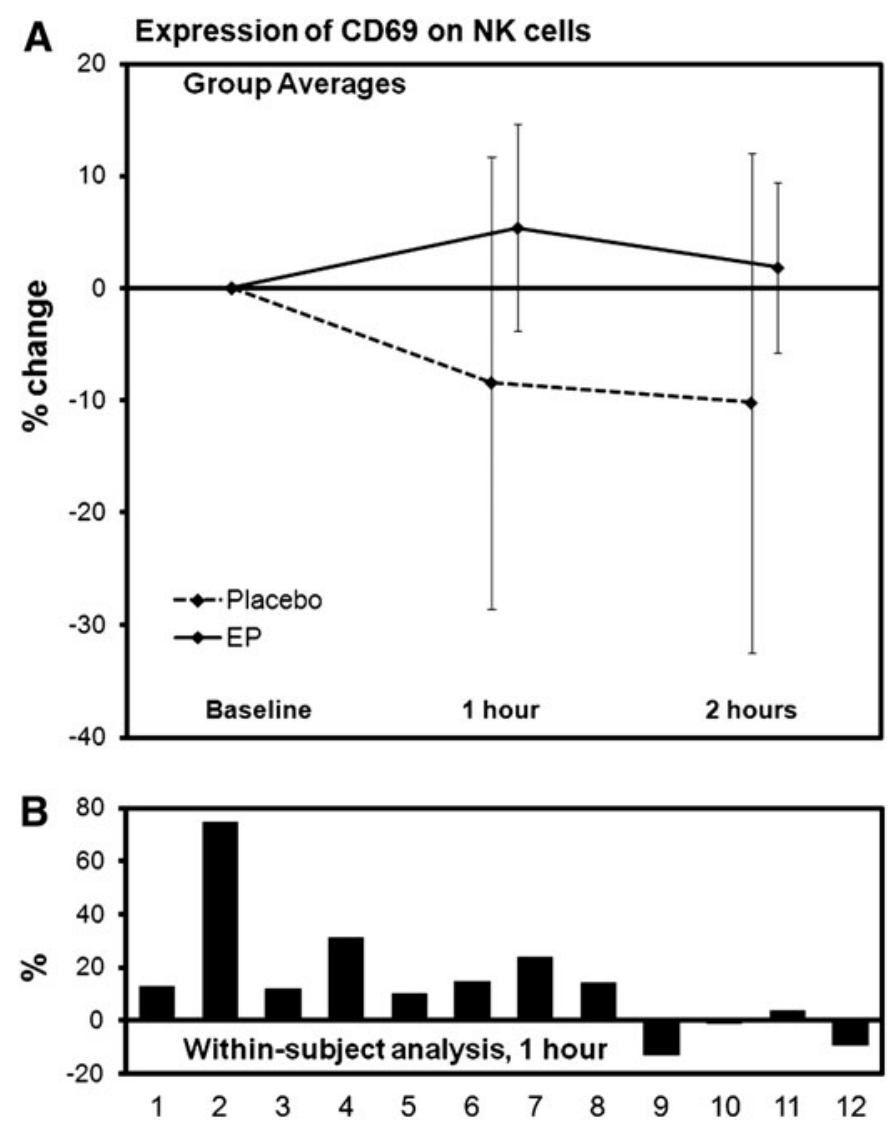

FIG. 5. Changes in expression of the CD69 activation marker on NK cells after consumption of placebo and $500 \mathrm{mg}$ of EP. (A) The group averages are shown for changes seen after consumption of placebo versus EP (mean $\pm \mathrm{SD}$ ). (B) The individual changes were compared for each subject to evaluate the change in each subject's response to EP in comparison with the same subject's response to placebo. These data were then analyzed using a within-subject paired $t$ test. The EP-induced increase over placebo was significant at 1 hour $(P<.05)$, but the statistical significance disappeared at 2 hours $(P<.15)$, indicating a rapid, but transient response.

associated with increased cytotoxic responsiveness, was increased on the surface of circulating NK cells. An increase in serum IFN- $\gamma$ levels was seen at 1 hour, which did not reach statistical significance $(P<.07)$. However, the trend to increased IFN- $\gamma$ content may be causative for the observed effects on NK cell activation and trafficking (Fig. 7). It is important to note that the increases in IFN and cytokine levels are mild and do not reflect a pathological state of inflammation. Our previous placebo-controlled 5-week study of EP consumption in healthy people showed trends toward increased IL-4, IL-6, and IL-10. ${ }^{19}$ This is in contrast to the acute effects reported here, where a mild reduction is seen in serum levels of IL-6 and IL-10. It is possible that the data reflect differential acute versus cumulative effects of EP consumption.

The data presented here were generated by using a study protocol that was carefully planned to be able to control for normal circadian variations in levels of circulating leuko- 

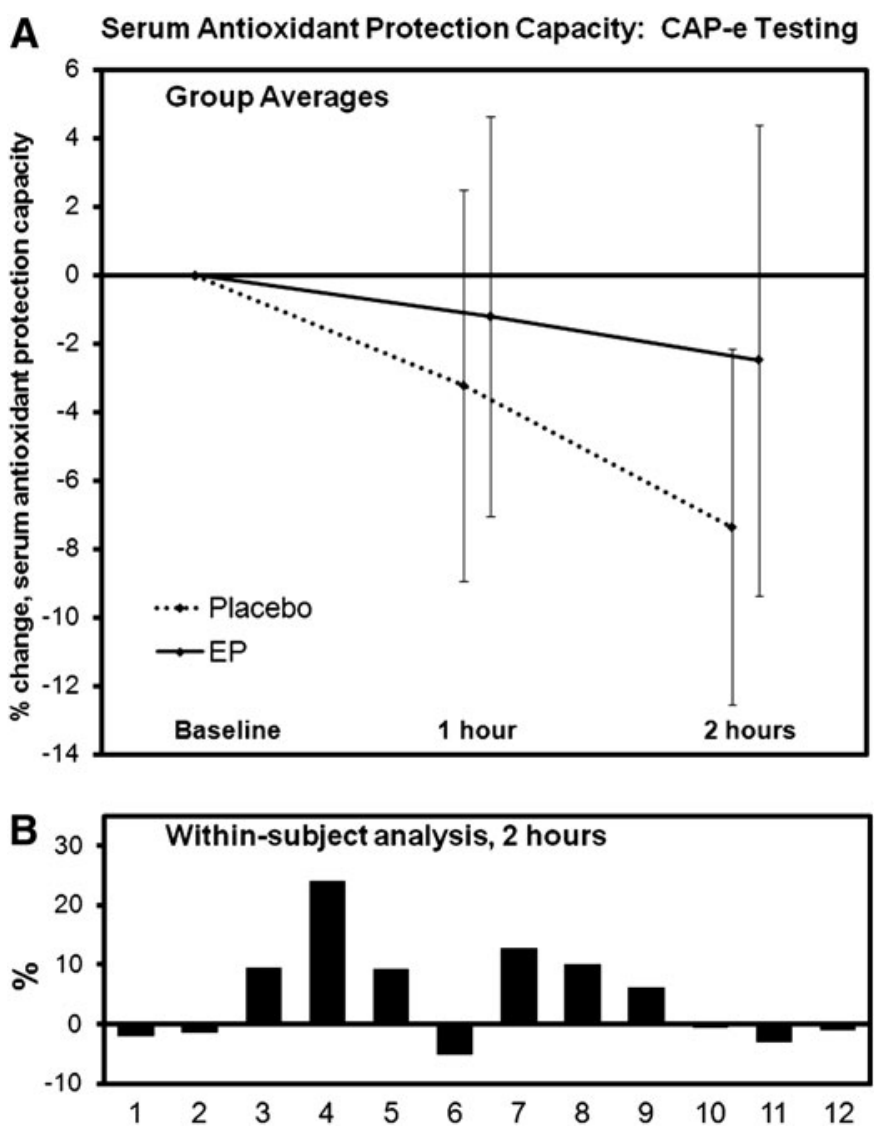

FIG. 6. Comparison of Cell-based Antioxidant Protection in Erythrocytes (CAP-e) data on a complex natural product, $\mathrm{EP}$, in vivo. EP consumption provided statistically significant improvement in serum antioxidant capacity, when serum samples obtained before and after consumption of either EP $(500 \mathrm{mg})$ or placebo were tested in quadruplicates using a double-blinded randomized crossover design. (A) The group averages are shown for changes seen after consumption of placebo versus EP (mean $\pm \mathrm{SD})$. (B) The individual changes were compared for each subject to evaluate the change in each subject's response to EP in comparison with the same subject's response to placebo. The within-subject paired $t$ test analysis of changes in serum antioxidant protection was calculated. The increased antioxidant protection after EP consumption was statistically significant at 2 hours after consumption $(P<.04)$.

cytes. The increase in total $\mathrm{T}$ cell numbers seen when placebo was consumed may reflect normal circadian rhythms, as it has been reported that $\mathrm{T}$ cell numbers are at a low level early in the morning and start to increase during the morning until noon. ${ }^{9,26}$ Our study protocol also aimed at a clinical study environment that controlled for psychological stress because acute stress negatively affects the biology of NK cells.

It is interesting that a trend toward decreased numbers of circulating $\mathrm{CD} 4^{+}$stem cells was observed $(P<.12)$. This mild trend may signify a transient induction of stem cell homing into tissues. Previously, consumable plant- and microbial-based products and pure compounds such as fucoidan have led to changes in circulating stem cells, in part due to changes in chemokine expression. ${ }^{27,28} \mathrm{EP}$ was
Table 3. Changes in Cytokine Levels in Serum After Consumption of EpiCor Versus Placebo

\begin{tabular}{lccc}
\hline & \multicolumn{2}{c}{ P value } & \\
\cline { 2 - 3 } & 1 hour & 2 hours & \% change \\
\hline IL-2 & NS & NS & \\
IL-4 & NS & NS & \\
IL-6 & $<.09$ & NS & -2.9 \\
IL-10 & NS & NS & \\
TNF- $\alpha$ & NS & NS & \\
IFN- $\gamma$ & NS & $<.05$ & $2.09^{\mathrm{a}}$ \\
\hline
\end{tabular}

The percentage change from baseline levels of serum cytokine levels was obtained from peripheral venous blood. A change of $2 \%$ at the peripheral level suggests changes at much higher levels locally, such as, for example, in the gut mucosal tissue. The percentage change and statistical significance were obtained on the study population of 12 volunteers except as noted. The withinsubject analysis and resulting $P$ value were obtained by performing the paired $t$ test.

${ }^{\mathrm{a}}$ The data on interferon- $\gamma($ IFN- $\gamma)$ were obtained after removal of data from volunteers 3 and 4 .

$\mathrm{IL}$, interleukin; TNF- $\alpha$, tumor necrosis factor- $\alpha$.

shown by our team to compete with fucoidan-induced changes to expression levels of several chemokine receptors on leukocytes. ${ }^{17}$ The observation may warrant further research on the effects of EP on human stem cell biology, including trafficking, such as we documented for extracts from another microbial-based food, namely, the microalga Aphanizomenon flos-aquae. ${ }^{28}$ It is possible that the effects are direct and may be linked to the existence of a selectin

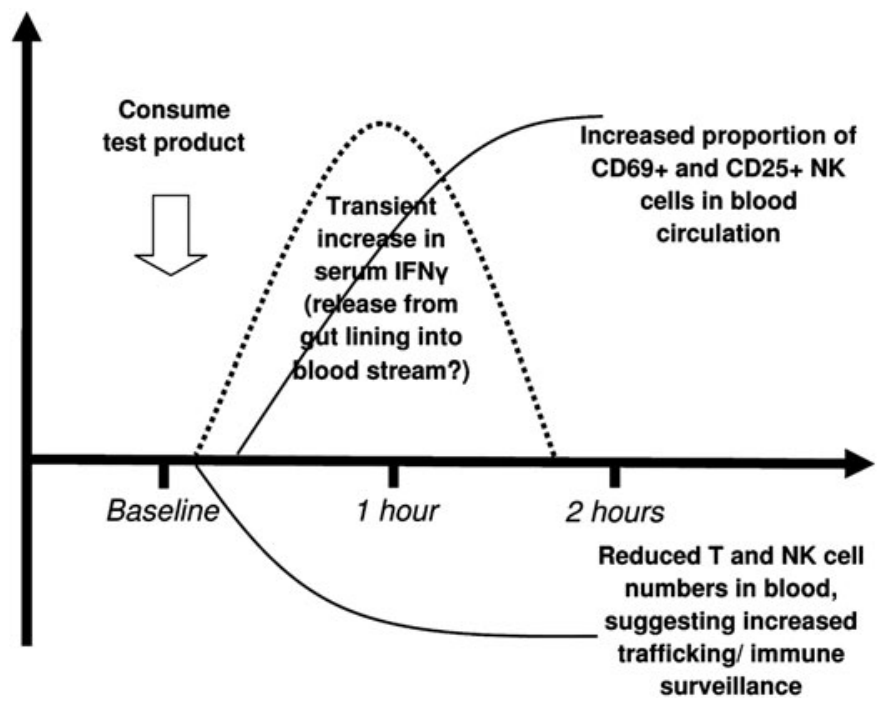

FIG. 7. Diagram showing proposed mechanisms of action leading to rapid effects on cytokine profile and immune surveillance after consumption of a single acute dose of $500 \mathrm{mg}$ of EP. The rapid increase in serum IFN- $\gamma$ levels may have contributed to the significant increase in the activation markers CD69 and CD25 on circulating $\mathrm{CD}^{-} \mathrm{CD}^{-} 6^{+} \mathrm{NK}$ cells, as well as help to explain the mild but significant transient reduction in circulating $\mathrm{T}$ cells and a similar trend for NK cells, indicative of increased immune surveillance. 
ligand in EP. ${ }^{17}$ Alternatively, the effect may be indirect and associated with anti-inflammatory effects of EP, reducing the negative impact of inflammation on stem cell phenotype and function.

We found a statistically significant improvement in serum antioxidant protection capacity after ingestion of $500 \mathrm{mg}$ of EP. This may reflect the content of easily absorbed antioxidants existing in the native product, as well as antioxidant compounds released or generated as a result of normal digestive processes. Unknown metabolites may contribute significantly to the in vivo antioxidant protection of EP. By using the CAP-e assay to evaluate the serum capacity for antioxidant protection, such metabolites do not need to be chemically identified; as long as they are able to enter and protect living cells from oxidative damage they contribute to the CAP-e results. This is in contrast to other types of bioavailability studies, where chemical analysis is performed on serum to examine the sample for metabolites known to have come from the digestion of a natural product.

The data presented here involved a healthy study population. Future work should address lymphocyte subsets in a broader manner, by including staining for the major $\mathrm{T}$ cell subsets including T-regulatory cells, as well as staining for B cells and dendritic cells. Further clinical work should address whether EP consumption may support immune surveillance in populations experiencing stress and sleep disturbances. EP consumption may hold promise as a nutritional immune support in healthy subjects under acute stress, as well as for patients with specific chronic illnesses affecting innate and adaptive immune defense mechanisms.

\section{ACKNOWLEDGMENTS}

The authors would like to thank Charlene Mogle, Wendy Zolczynski, Dana Honzel, Ariston Vallejos, and Carly Cox for their excellent technical assistance. The study was performed at NIS Labs, an independent contract research lab specializing in natural products research, and sponsored by Embria Health Sciences Inc.

\section{AUTHOR DISCLOSURE STATEMENT}

G.S.J., K.A.R., K.F.B., S.G.C., and M.A.M. are employees of NIS Labs. S.R. and L.R. are employees of Embria Health Sciences Inc.

\section{REFERENCES}

1. Klimas NG, Koneru AO: Chronic fatigue syndrome: inflammation, immune function, and neuroendocrine interactions. Curr Rheumatol Rep 2007;9:482-487.

2. Buskila D, Atzeni F, Sarzi-Puttini P: Etiology of fibromyalgia: the possible role of infection and vaccination. Autoimmun Rev 2008;8:41-43.

3. Ortega-Hernandez OD, Shoenfeld Y: Infection, vaccination, and autoantibodies in chronic fatigue syndrome, cause or coincidence? Ann N Y Acad Sci 2009;1173:600-609.

4. Caligiuri MA: Human natural killer cells. Blood 2008;112:461469.
5. Sutlu T, Alici E: Natural killer cell-based immunotherapy in cancer: current insights and future prospects. J Intern Med 2009;266:154181.

6. Meeus M, Mistiaen W, Lambrecht L, Nijs J: Immunological similarities between cancer and chronic fatigue syndrome: the common link to fatigue? Anticancer Res 2009;29:4717-4726.

7. Arjona A, Sarkar DK: Evidence supporting a circadian control of natural killer cell function. Brain Behav Immun 2006;20:469476.

8. Bollinger T, Bollinger A, Skrum L, Dimitrov S, Lange T, Solbach W: Sleep-dependent activity of $\mathrm{T}$ cells and regulatory $\mathrm{T}$ cells. Clin Exp Immunol 2009;155:231-238.

9. Dimitrov S, Benedict C, Heutling D, Westermann J, Born J, Lange T: Cortisol and epinephrine control opposing circadian rhythms in T cell subsets. Blood 2009;113:5134-5143.

10. Shakhar K, Valdimarsdottir HB, Guevarra JS, Bovbjerg DH: Sleep, fatigue, and NK cell activity in healthy volunteers: significant relationships revealed by within subject analyses. Brain Behav Immun 2007;21:180-184.

11. Tsujimura T, Matsuo Y, Keyaki T, Sakurada K, Imanishi J: Correlations of sleep disturbance with the immune system in type 2 diabetes mellitus. Diabetes Res Clin Pract 2009;85:286292.

12. Cardinali DP, Esquifino AI, Srinivasan V, Pandi-Perumal SR: Melatonin and the immune system in aging. Neuroimmunomodulation 2008;15:272-278.

13. Witek-Janusek L, Albuquerque K, Chroniak KR, Chroniak C, Durazo-Arvizu R, Mathews HL: Effect of mindfulness based stress reduction on immune function, quality of life and coping in women newly diagnosed with early stage breast cancer. Brain Behav Immun 2008;22:969-981.

14. de Pascual-Teresa S, Moreno DA, García-Viguera C: Flavanols and anthocyanins in cardiovascular health: a review of current evidence. Int J Mol Sci 2010;11:1679-1703.

15. Jensen GS, Wu X, Patterson KM, Barnes J, Carter SG, Scherwitz L, Beaman R, Endres JR, Schauss AG: In vitro and in vivo antioxidant and anti-inflammatory capacities of an antioxidant-rich fruit and berry juice blend. Results of a pilot and randomized, double-blinded, placebo-controlled, crossover study. J Agric Food Chem 2008;56:8326-8333.

16. Honzel D, Carter SG, Redman KA, Schauss AG, Endres JR, Jensen GS: Comparison of chemical and cell-based antioxidant methods for evaluation of foods and natural products: generating multifaceted data by parallel testing using erythrocytes and polymorphonuclear cells. J Agric Food Chem 2008;56:83198325.

17. Jensen GS, Hart AN, Schauss AG: An antiinflammatory immunogen from yeast culture induces activation and alters chemokine receptor expression on human natural killer cells and B lymphocytes in vitro. Nutr Res 2007;27:327335.

18. Jensen GS, Patterson KM, Yoon I: Yeast culture has anti-inflammatory effects and specifically activates NK cells. Comp Immunol Microbiol Infect Dis 2008;31:487-500.

19. Jensen GS, Patterson KM, Barnes J, Schauss AG, Beaman R, Reeves SG, Robinson LE: A double-blind placebo-controlled, randomized pilot study: consumption of a high-metabolite immunogen from yeast culture has beneficial effects on erythrocyte health and mucosal immune protection in healthy subjects. Open Nutr J 2008;2:68-75. 
20. Moyad MA, Robinson LE, Zawada ET Jr, Kittelsrud JM, Chen DG, Reeves SG, Weaver SE: Effects of a modified yeast supplement on cold/flu symptoms. Urol Nurs 2008;28: 50-55.

21. Moyad MA, Robinson LE, Zawada ET, Kittelsrud JM, Chen DG, Reeves SG, Weaver SE: Immunogenic yeast-based fermentate for cold/flu-like symptoms in non-vaccinated individuals. $J \mathrm{Al}$ tern Complement Med 2010;16:213-218.

22. Moyad MA, Robinson LE, Kittelsrud JM, Reeves SG, Weaver SE, Guzman AI, Bubak ME: Immunogenic yeast-based fermentation product reduces allergic rhinitis-induced nasal congestion: a randomized, double-blind, placebo-controlled trial. Adv Ther 2009;26:795-804.

23. Shephard RJ: Adhesion molecules, catecholamines and leucocyte redistribution during and following exercise. Sports Med 2003;33:261-284.

24. Atanackovic D, Schnee B, Schuch G, Faltz C, Schulze J, Weber CS, Schafhausen P, Bartels K, Bokemeyer C, Brunner-Weinzierl MC, Deter HC: Acute psychological stress alerts the adaptive immune response: stress-induced mobilization of effector T cells. J Neuroimmunol 2006;176:141-152.

25. Atanackovic D, Brunner-Weinzierl MC, Kröger H, Serke S, Deter HC: Acute psychological stress simultaneously alters hormone levels, recruitment of lymphocyte subsets, and production of reactive oxygen species. Immunol Invest 2002;31:7391.

26. Dimitrov S, Lange T, Nohroudi K, Born J: Number and function of circulating human antigen presenting cells regulated by sleep. Sleep 2007;30:401-411.

27. Irhimeh MR, Fitton JH, Lowenthal RM: Fucoidan ingestion increases the expression of CXCR4 on human CD34+ cells. Exp Hematol 2007;35:989-994.

28. Jensen GS, Hart AN, Zaske LA, Drapeau C, Gupta N, Schaeffer DJ, Cruickshank JA: Mobilization of human CD34 + CD133 + and CD34 + CD133(-) stem cells in vivo by consumption of an extract from Aphanizomenon flos-aquae-related to modulation of CXCR4 expression by an L-selectin ligand? Cardiovasc Revasc Med 2007;8:189-202. 